\title{
O direito à cidade e o desenvolvimento local como base para a humanização do espaço urbano
}

\author{
The right to the city and the local development as a base for the humanization \\ of the urban space
}
Le droit de la ville et le développement local comme base de l'humanisation de l'espace urbain

\section{El derecho a la ciudad y el desarrollo local como base para la humanización del espacio urbano}

\author{
Lina Yule Queiroz de Oliveira ${ }^{1}$ \\ Pedro Pereira Borges ${ }^{1}$ \\ Recebido em 19/06/2017; revisado e aprovado em 01/10/2017; aceito em 14/11/2017 \\ DOI: http://dx.doi.org/10.20435/inter.v19i4.1630
}

\begin{abstract}
Resumo: Este artigo tem como tema a humanização das cidades e objetiva identificar o direito à cidade e o desenvolvimento local como instrumentos de efetivação da humanização do espaço urbano. A pesquisa é bibliográfica e procurou interpretar e correlacionar reflexões de autores referência nas temáticas tratadas como Lefebvre, Harvey, Jacobs, Gehl, Ávila e Max-Neef. O estudo ressaltou a importância do desenvolvimento local e do direito à cidade como eixos de políticas públicas e formas de alcançar o protagonismo do ser humano nas cidades.
\end{abstract}

Palavras-chave: direito à cidade; desenvolvimento local; humanização; urbanismo.

Abstract: This article has as its theme the humanization of cities and it aims to identify the right to the city and local development as tools for the humanization of urban space. The research is bibliographical and sought to interpret and to correlate reflections of reference authors in the themes treated, such as Lefebvre, Harvey, Jacobs, Gehl, Ávila and Max-Neef. The study emphasized the importance of local development and the right to the city as public policies axes and ways of achieving the protagonism of the human being in the cities. Keywords: right to the city; local development; humanization; urbanism.

Résumé: Cet article met l'accent sur le droit à la ville et le développement local comme instruments efficaces de l'humanisation espace urbain et il est analysé du point de vue des besoins humains et des citoyens en tant que protagonistes de l'espace public. La recherche est la littérature et ont cherché à interpréter et établir une corrélation entre les réflexions des auteurs comme Henri Lefebvre et David Harvey sous le droit à la ville, Jane Jacobs et Jan Gehl dans la région des villes humaines et Avila et Max-Neef dans le domaine du développement local, et met l'accent sur la importance du développement local et le droit à la ville comme des moyens d'atteindre la dimension humaine dans l'espace urbain et la façon dont les axes de la politique publique.

Mots-clés: droit à la ville; développement local; humanisation; urbanisme.

Resumen: El artículo tiene como tema el derecho a la ciudad y el desarrollo local como instrumentos de efectivización de la humanización del espacio urbano y éste es analizado a partir de las necesidades humanas y de la perspectiva de los ciudadanos como protagonistas del espacio público. La investigación es bibliográfica y trató de interpretar y correlacionar reflexiones de autores como Henri Lefebvre y David Harvey en el ámbito del derecho a la ciudad, Jane Jacobs y Jan Gehl en el área de ciudades humanas y Ávila y Max-Neef en el campo de desarrollo local, y resalta Importancia del desarrollo local y del derecho a la ciudad como formas de alcanzar la dimensión humana en el espacio urbano y como ejes de las políticas públicas.

Palabras-clave: derecho a la ciudad; desarrollo local; humanización; urbanismo.

\footnotetext{
${ }^{1}$ Universidade Católica Dom Bosco (UCDB), Campo Grande, Mato Grosso do Sul, Brasil.
} 


\section{INTRODUÇÃO}

Este trabalho tem como tema a humanização das cidades, o que implica um planejamento urbano que valoriza a escala humana, a fim de que os cidadãos sejam protagonistas do espaço público. Os ideais dominantes de planejamento, particularmente o modernismo, negligenciaram seriamente a dimensão humana nas cidades por quase 70 anos. Os modelos de planejamento urbano adotados nas últimas décadas, além de contribuir para o espraiamento urbano e segregação socioespacial, contribuíram também para desumanizar ambientes urbanos em termos de escala ou sentido de pertencimento.

É essencial que o espaço urbano atenda às necessidades de seus habitantes, onde as políticas públicas devem estar voltadas para a humanização das cidades e para garantir o bem-estar dos cidadãos. Frente a essa realidade e a necessidade de pensar, criar e lutar por cidades para todos, o presente artigo objetiva identificar o direito à cidade e o desenvolvimento local como instrumentos de efetivação da humanização do espaço urbano. Esses dois aportes podem assegurar que as pessoas exerçam a cidadania, apropriando-se de uma cidade justa, humana e democrática, garantindo o planejamento local participativo, o acesso à cidade, aos equipamentos urbanos e às oportunidades sociais, educacionais, políticas, econômicas e culturais.

Para tanto, foram analisados os aspectos teóricos do direito à cidade e do desenvolvimento local, na intenção de provocar maiores reflexões sobre as práticas de planejamento urbano atuais. Os princípios do planejamento urbano moderno foram descritos a fim de identificar as consequências que ele causou nas cidades, na qualidade do espaço urbano e na qualidade de vida urbana. Desse modo, o artigo apresenta elementos para uma reflexão teórica sobre os modelos de planejamento implementados nas cidades.

A metodologia deste artigo baseou-se em pesquisa bibliográfica, tendo sido elaborada interpretando e correlacionando diferentes reflexões de autores-chave para a discussão da temática. Inicialmente foram contextualizados os conceitos de direito à cidade focando nos estudos de Lefebvre e de Harvey, autores que são referência na temática e abordam a alteração do espaço urbano pelos meios de produção.

Em seguida, identificaram-se os ideais modernistas de desenvolvimento e planejamento urbano, e as diferentes maneiras com que as cidades foram afetadas por eles, retratadas com precisão por Jane Jacobs e Jan Gehl. Posteriormente, os conceitos de desenvolvimento local e cidades para pessoas foram detalhados, utilizando o aporte teórico de Ávila e Max-Neef. Por fim, retomou-se o direito à cidade enfatizando a importância das políticas públicas voltadas para o protagonismo dos cidadãos e da participação ativa no planejamento urbano.

Com essa discussão, ressaltou-se a importância do desenvolvimento local, que possui o ser humano no centro de suas práticas, e o direito à cidade como eixo do planejamento e das políticas urbanas. O trabalho demonstra a importância da escala no processo de planejamento e desenvolvimento urbano e de uma política urbana unificada que incorpora a dimensão humana, buscando reabilitar o espaço urbano com ênfase no nível local, priorizando os cidadãos.

\section{O DIREITO À CIDADE}

O termo "direito à cidade" foi cunhado pelo filósofo e sociólogo Henri Lefebvre, em sua obra publicada em 1968 "O Direito à Cidade" (Le Droit à la Ville). Lefebvre reflete a problemática urbana a partir da consolidação do modo de produção capitalista e da industrialização, característica da sociedade moderna e motor de suas transformações. 
Enfatiza Lefebvre (2001) que a cidade possui relações com a sociedade em seu conjunto, assim como com a sua composição, funcionamento, elementos constituintes e com sua história, consequentemente, a cidade muda, sempre, quando a sociedade em seu conjunto também muda. A cidade é uma projeção da sociedade sobre um local, história e obra de uma história, de pessoas e grupos que realizam essa obra em condições históricas e das relações sociais que existem nela. Logo, o espaço urbano é resultado das ações dos sujeitos sobre o próprio espaço, surgindo como a forma com que eles se relacionam no e com o espaço.

Os processos globais - econômicos, sociais, políticos, culturais - modelaram o espaço urbano de acordo com seus interesses, permitindo a influência e sua transformação pelos grupos sociais que se apropriaram do espaço, onde, segundo Lefebvre (2001, p. 57), "essas transformações da vida cotidiana modificaram a realidade urbana, não sem tirar dela suas motivações. A cidade foi ao mesmo tempo o local e o meio, teatro e arena dessas interações complexas". Além disso, a cidade se transformou, não apenas com os processos globais, mas também com as modificações profundas no modo de produção e as relações de classe e propriedade, com a industrialização sendo o indutor dos problemas de crescimento, do desenvolvimento da realidade urbana e das questões relativas à cidade (LEFEBVRE, 2001).

Se o desenvolvimento da sociedade urbana é subordinado ao crescimento industrial, o processo de urbanização e industrialização perde seu sentido. A cidade como centro da vida social e política, é uma obra, com valor de uso e valor de troca. No entanto a cidade e a realidade urbana dependem do valor de uso, uma vez que "o valor de troca e a generalização da mercadoria pela industrialização tendem a destruir, ao subordiná-las a si, a cidade e a realidade urbana" (LEFEBVRE, 2001, p. 14).

Uma das análises que Lefebvre traz em seu texto, é a reforma urbanística promovida em Paris, em 1848, pelo Barão Georges Haussmann, como uma maneira de remodelar o espaço urbano na via do valor de troca, visando ao remanejamento da cidade como uma estratégia de classe, expulsando os trabalhadores para os subúrbios, destituindo-os da vida urbana. Como uma maneira de frear a democracia urbana impulsionada pelas lutas populares - uma ameaça aos interesses das classes dominantes - a segregação dos trabalhadores e novo ordenamento territorial do tecido urbano foi o modo encontrado para estabelecer controle e anular a principal característica das cidades na época, o espaço urbano como local de encontro e convívio, como uma forma de participar de uma vida social (LEFEBVRE, 2001).

A vida urbana, assinala Lefebvre (2001) pressupõe encontros e confrontos das diferenças, dos conhecimentos e dos reconhecimentos recíprocos dos modos de viver, dos padrões que coexistem na cidade. $\mathrm{O}$ autor considera então que o direito à cidade deve ser compreendido como um apelo, uma exigência, como o direito à vida urbana, condição de um humanismo e de uma democracia transformados, renovados. Direito aos locais de encontro e de trocas, de ritmos de vida e do uso pleno desses locais e momentos, direito à produção do espaço urbano como uma construção coletiva:

O direito à cidade se manifesta como forma superior dos direitos: direito à liberdade, à individualização na socialização, ao habitat e ao habitar. O direito à obra (à atividade participante) e o direito à apropriação (bem distinto do direito à propriedade) estão implicados no direito à cidade. (LEFEBVRE, 2001, p. 134).

O direito à cidade, portanto, seria o direito de usufruir do espaço urbano como o reino do uso e do encontro separados do valor de troca, do domínio do econômico, do mercado e da mercadoria, exigindo o rompimento com a lógica capitalista de produção do espaço. 
Com a suburbanização, inicia-se um processo que descentraliza a cidade, afastando o proletariado dos centros de produção e instalando uma periferia desurbanizada, porém dependente da cidade. Os subúrbios residenciais para a burguesia também se instalam e o centro se esvazia em benefício de um uso quase que puramente comercial, tornando-se um local de consumo. $\mathrm{O}$ reordenamento espacial, a lógica capitalista e seu ritmo de produção do espaço dominam Paris, seu centro urbano como local de consumo privilegiado, com a estratégia global de concretizar a sociedade de consumo dirigida, impondo "uma ideologia da felicidade através do consumo, a alegria através do urbanismo adaptado à sua nova missão. Este urbanismo programa uma cotidianidade geradora de satisfações. O consumo programado e cibernetizado [...] tornar-se-á regra e norma para a Sociedade inteira" (LEFEBVRE, 2001, p. 32).

A cidade encarada como arena para o consumo desloca a ênfase do desenvolvimento urbano em atender às necessidades da comunidade para atender às necessidades de indivíduos, como apontam Rogers e Gumuchdjian (2001), resultando no declínio da vitalidade urbana e na polarização da sociedade. Desse modo, em lugar das relações de valor de uso, as relações de valor de troca passam a ser dominantes, com todas as condições mantidas para exercer 0 domínio e exploração das pessoas, como produtores, consumidores de produtos e consumidores de espaço. A convergência desses fatores, para Lefebvre (2001), apresenta politicamente o problema da sociedade urbana.

Somente quando a política se concentrar na produção e reprodução da vida urbana como processo de trabalho essencial, reforça Harvey (2014, p. 21), é que será possível concretizar lutas e revoluções urbanas capazes de transformar radicalmente a vida cotidiana. Somente quando compreenderem que os que constroem e mantêm a vida urbana têm uma exigência fundamental sobre o que foi produzido, sobre o "direito inalienável de criar uma cidade mais em conformidade com seus verdadeiros desejos".

A ideia do direito à cidade, para Harvey (2014, p. 15), "não surge fundamentalmente de diferentes caprichos e modismos intelectuais [...]. Surge basicamente das ruas, dos bairros, como um grito de socorro e amparo de pessoas oprimidas em tempos de desespero". David Harvey é um dos principais nomes da geografia humana da atualidade, inspirando-se nas ideias de Lefebvre para analisar, especialmente, a ligação entre urbanização e capitalismo, trançando paralelos entre o processo de reurbanização de Paris por Haussmann e o projeto de urbanização de Robert Moses em Nova York no pós-guerra, salientando o crescimento das cidades como sintoma da crise de acumulação capitalista.

A experiência prática demonstra que é possível haver crescimento sem desenvolvimento social - crescimento quantitativo, sem desenvolvimento qualitativo- subordinando o desenvolvimento ao crescimento econômico. O desenvolvimento de uma sociedade só pode ser concebido, esclarece Lefebvre (2001), na vida urbana, pela realização da sociedade, o que exige uma estratégia voltada para as necessidades sociais, para as necessidades humanas e da sociedade urbana. Igualmente indispensável é a existência de uma força social e política capaz de operar esses meios.

Robert Park, famoso sociólogo urbanista, descreve a cidade como:

[...] algo mais do que um amontoado de homens individuais e de conveniências sociais, ruas, edifícios, luz elétrica, linhas de bonde, telefones etc.; algo mais também do que uma mera constelação de instituições e dispositivos administrativos - tribunais, hospitais, escolas, polícia e funcionários civis de vários tipos. Antes, a cidade é um estado de espírito, um 
corpo de costumes e tradições e dos sentimentos e atitudes organizados, inerentes a esses costumes e transmitidos por essa tradição. Em outras palavras, a cidade não é meramente um mecanismo físico e uma construção artificial. Está envolvida nos processos vitais das pessoas que a compõem; é um produto da natureza, e particularmente da natureza humana. (PARK, 1925, p. 1).

Dessa forma, o tipo de cidade que as pessoas querem está diretamente vinculado ao tipo de pessoas que elas querem ser, ao tipo de relação social que elas buscam, como ao tipo de relação com a natureza que as satisfaz e também com o estilo de vida que elas procuram levar e seus valores estéticos (HARVEY, 2014). Logo, o direito à cidade não é apenas um direito de acesso individual ou grupal aos recursos urbanos, mas sim um direito de reinventar a cidade de acordo com os desejos de cada um, sendo um direito mais coletivo que individual, pois reinventar a cidade implica no exercício de um poder coletivo. É a liberdade de "fazer e refazer a nós mesmos e a nossas cidades, [...], é um dos nossos direitos humanos mais preciosos, ainda que um dos mais menosprezados" (HARVEY, 2014, p. 28).

Reivindicar o direito à cidade, por conseguinte, equivale a reivindicar alguma forma de poder configurador sobre o processo de urbanização, sobre o modo como as cidades são feitas e refeitas, a fim de moldar o espaço urbano de acordo com as necessidades da sociedade, e não de uma minoria (HARVEY, 2014).

\section{A FALÁCIA DO PLANEJAMENTO E DO DESENHO URBANÍSTICO ORTODOXO MODERNO}

Assim como Lefebvre começa seu livro "O Direito à Cidade" (1968) com a frase "Este livro terá uma forma ofensiva.", Jane Jacobs inicia sua obra "Morte e Vida das Grandes Cidades" (1961) com a afirmação "Este livro é um ataque.". Ambos questionam o urbanismo como ideologia e reforçam a importância do respeito da complexidade da experiência urbana e suas redes de relação. Os autores também compartilham formas de reapropriação do tecido urbano, rejeitam os princípios que moldaram a reurbanização e o planejamento urbano modernista e elucidam o papel da vida cotidiana na construção e apropriação das cidades.

Jacobs, jornalista, escritora e ativista política, foi um dos principais nomes que mudaram a forma de observar a analisar as cidades. A autora pregava que compreender o funcionamento das cidades na prática é a única maneira de saber que princípios de planejamento e iniciativas de reurbanização seguir, para entender quais conseguem realmente promover a vitalidade socioeconômica nas cidades e quais a inviabilizam.

No caso do planejamento urbano, Jacobs $(2011$, p. 6) reconhece que há uma grande quantidade de pessoas que se preocupam com o processo urbano, no entanto são profissionais que ainda agem de acordo com as teorias que possuem sobre as cidades, não desprezando conscientemente a importância de conhecer o funcionamento das coisas:

Ao contrário, esforçaram-se muito para aprender o que os santos e os sábios do urbanismo moderno ortodoxo disseram a respeito de como as cidades deveriam funcionar e o que deveria ser bom para o povo e os negócios dentro delas. Eles se aferram a isso com tal devoção, que, quando uma realidade contraditória se interpõe, ameaçando destruir o aprendizado adquirido a duras penas, eles colocam a realidade de lado. (JACOBS, 2011, p. 6).

Dessa forma, o espaço urbano é projetado a partir de interpretações e teorias, e não a partir das significações percebidas e vividas por seus habitantes. Ao racionalizar as cidades, esses profissionais caem no erro de ignorar a escala de vida, projetando as cidades de acordo 
com teorias do que deve funcionar, e não do que realmente funciona. Afirma Jacobs (2011) que, como em outras pseudociências, no campo do planejamento urbano, anos de aprendizagem e vasta quantidade de dogmas apoiaram-se em um alicerce de absurdos. A pseudociência do planejamento urbano e a arte do desenho urbano, "ainda não se afastaram do conforto ilusório das vontades, das superstições conhecidas, do simplismo e dos símbolos e ainda não se lançaram na aventura de investigar o mundo real" (JACOBS, 2011, p. 12).

O conceito de cidade enquanto espaço de consumo e rede de circulação, para Lefebvre (2001), é uma ideologia absoluta, possuindo dois aspectos solidários, um mental e um social: mentalmente, implica uma teoria da racionalização e organização; socialmente, implica a noção de espaço em primeiro plano, transpondo os problemas urbanos e sociais em questões espaciais. O urbanismo como ideologia, evidencia Lefebvre (2001), interpreta os conhecimentos parciais e justifica as suas aplicações, elevando-as a uma totalidade mal fundamentada ou mal legitimada, formulando todos os problemas da sociedade em questões de espaço.

Para Jacobs (2011), as ideias ortodoxas de planejamento urbano são prejudiciais porque são encaradas como naturais. A autora identifica as linhas gerais das ideias influentes que mais contribuíram para o planejamento e desenho urbano ortodoxo modernista, iniciando com a proposta das Cidades-Jardim, de Ebenezer Howard, em 1898.

Sua proposta era uma reação à cidade vitoriana, encortiçada, buscando exportar parte da população das cidades para novas cidades construídas em campo aberto, distantes dos altos valores da terra, da poluição, miséria e dos cortiços (HALL, 2016). O plano envolvia conter o crescimento de Londres e repovoar a zona rural, unindo o campo e a cidade, criando cidades autossuficientes. Howard trouxe a tona "ideias efetivas para a destruição das cidades", separando seus usos, restringindo as atividades humanas e isolando a cidade com as características e serviços de um bairro autossuficiente (JACOBS, 2011).

Para Howard (1902, p. 17), a "sociedade humana e a beleza da natureza foram feitas para serem apreciadas juntas", devendo-se, desse modo, unir as atrações das cidades com as atrações do campo, resultando em uma nova civilização. A chave de tudo, para Howard, era que os cidadãos fossem proprietários perpétuos de suas terras. A cidade-jardim teria como foco o gerenciamento local e o autogoverno, propondo um novo sistema socioeconômico (HALL, 2016).

Howard concebia o planejamento urbano como uma série de ações estáticas, esclarece Jacobs (2011, p. 18), não se interessando pelos aspectos urbanos que não pudessem servir à sua utopia, descartando principalmente "a complexa e multifacetada vida cultural da metrópole. Não tinha interesse em questões como segurança pública, troca de ideias, funcionamento político ou criação de novas saídas econômicas nas grandes cidades, nem dava atenção à criação de novas maneiras de fortalecer essas atribuições, porque, afinal, esse tipo de vida não estava em seus planos". Jacobs pontua que Howard poderia ser justificável sob seu ponto de vista, mas de forma alguma sob o ponto de vista urbanístico, e "ainda assim, praticamente todo o planejamento urbano moderno é uma adaptação ou um remendo desse material absurdo" (JACOBS, 2011, p. 18).

As ideias de Howard influenciaram o biólogo e filósofo Sir Patrick Geddes, autor de conceitos urbanísticos que se tornaram clássicos, exercendo uma grande influência quando se realizaram as primeiras Cidades-Jardim (CHOAY, 2003). Hall (2016, p. 353) afirma que Geddes “mais do que ninguém, é responsável por trazer à teoria do planejamento urbano a idéia de que homens e 
mulheres poderiam construir suas próprias cidades, escapando, assim, da massificação industrial para um mundo de atividade artesanal". Geddes discorreu sobre a evolução das cidades e imaginava seu planejamento em termos de planejamento de regiões inteiras, buscando, como Howard, frear o crescimento urbano.

Durante os anos 20, as ideias de Howard e Geddes foram adotadas e ampliadas pelos chamados "descentralizadores", entre eles, Lewis Mumford, Clarence Stein, Henry Wright e Catherine Bauer, que buscavam descentralizar as cidades, reduzindo-as, e dispersar a população em cidades menores e separadas. De acordo com Jacobs (2011), esse grupo popularizou ideias que são inquestionáveis no urbanismo ortodoxo, como:

[...] a rua é um lugar ruim para os seres humanos; as casas devem estar afastadas dela e voltadas para dentro, para uma área verde cercada. [...] A unidade básica do traçado urbano não é a rua, mas a quadra, mais particularmente, a superquadra. O comércio deve ser separado das residências e das áreas verdes. A demanda de mercadorias de um bairro deve ser calculada "cientificamente", e o espaço destinado ao comércio deve ater-se a isso, e a nada mais. [...] o bom planejamento urbano deve almejar pelo menos a ilusão de isolamento e privacidade, como num subúrbio. Os descentralizadores também insistiram nas premissas de Howard de que uma comunidade planejada deve ser ilhada, como uma unidade autossuficiente, deve resistir a mudanças futuras e todos os detalhes significativos devem ser controlados pelos planejadores desde o início e mantidos dessa maneira. Em suma, o bom planejamento era o planejamento previamente projetado. (JACOBS, 2011, p. 20).

Não procuravam entender como as cidades funcionavam ou sobre sua manutenção e não possuíam tal intenção. Suas ideias foram assimiladas na abordagem construtiva das cidades, onde as pessoas que procuraram fortalecer as cidades acabaram por adotar essas medidas, que minavam sua economia, e por destruí-las. Inspiravam-se na ideia de cidade-jardim de Howard, propondo "uma 'forma urbana utópica', em que uma grande variedade de comunidades urbanas estaria situada em um contínuo plano de fundo verde de fazendas, parques e áreas selvagens" (HALL, 2016, p. 205).

No entanto, para Jacobs, foi o arquiteto modernista Le Corbusier que teve a maior proposta de planejamento anticidade, a Ville Radieuse, uma cidade vertical composta por arranha-céus dentro de um parque, assimilando a imagem fundamental da Cidade-Jardim, e tornando-a prática em locais densamente povoados, chamando-a de 'Cidade-Jardim vertical'.

Le Corbusier teve seu trabalho marcado por uma racionalização excessiva, buscando a eficiência acima de tudo, componente essencial na 'sociedade da máquina', como ele chamava a sociedade da época. Pregava a organização nas cidades e a separação de suas funções, denominando cada uma por 'unidades' - unidades de habitação, de trabalho, circulação, paisagem (LE CORBUSIER, 2000). Sua proposta não era uma reação à industrialização ou ao maquinismo, mas sim uma adequação a essa nova era, a era de produção em massa:

A grande indústria deve se ocupar da construção e estabelecer em série os elementos da casa. É preciso criar o estado de espírito em série. O estado de espírito de construir casas em série. $\mathrm{O}$ estado de espírito de residir em casas em série. O estado de espírito de conceber casas em série. (LE CORBUSIER, 2002, p. 159).

O arquiteto idealizava que, nos próximos anos, a indústria e a organização financeira resolveria o problema das habitações, onde as construções seriam "imensas, geridas e exploradas como administrações", com loteamentos urbanos vastos e ortogonais- e não mais disformes permitindo o emprego do elemento em série e a industrialização da construção (LE CORBUSIER, 
2002). Sua cidade era ordenada, de fácil compreensão, com grandes vias expressas e ruas para transportes e separação dos pedestres das ruas.

A proposta de Le Corbusier teve um grande impacto no planejamento urbano, já que, além de tornar os princípios superficiais da Cidade-Jardim aplicáveis a cidades densamente povoadas, também tornava os automóveis um elemento fundamental em seu projeto. Le Corbusier ansiava por cidades ordenadas, e a massificação da arquitetura seria um instrumento capaz de resolver os problemas urbanos da época.

Observa Hall (2016) que permanecem entre nós as consequências deletérias do planejamento autoritário de Le Corbusier, a quem chama de o Rasputin da história do urbanismo. Os projetos de planejamento urbano hoje harmonizam vários aspectos das duas concepções, elas são seus pontos de partida. Os Congressos Internacionais de Arquitetura Moderna e a Carta de Atenas, documento-síntese do pensamento urbanístico que pregava a setorização das funções da cidade, também contribuíram amplamente para os princípios do urbanismo moderno serem disseminados mundialmente.

A Carta de Atenas, escrita por Le Corbusier, teve todos seus princípios aplicados integralmente em Brasília por Lúcio Costa, autor do plano piloto da capital. Planejada em 1956, a partir dos ideais modernistas, Brasília permite a análise das consequências dessa forma de planejamento, voltada exclusivamente para a grande escala. O urbanista Jan Gehl, referência mundial em desenho urbano e espaços públicos e especialista em criar 'cidades para pessoas', afirma que, embora vista do alto Brasília seja uma bela composição, é na pequena escala que é possível observar seus problemas.

Gehl denomina de 'Síndrome de Brasília' o modo modernista de projetar que desconsidera a chamada escala humana, onde a forma de projetar considera apenas a grande escala, com o planejamento 'do alto e de fora'. Na escala de vida, a cidade ao nível dos olhos, Brasília é uma catástrofe: "os espaços urbanos são muito grandes e amorfos, as ruas muito largas e as calçadas e passagens muito longas e retas. As grandes áreas verdes são atravessadas por caminhos abertos pela passagem de pessoas, mostrando como os habitantes se revoltaram, com os pés, contra o rígido plano formal da cidade" (GEHL, 2013, p. 197).

Os princípios urbanos modernistas projetam para a realidade a ideologia de uma prática que visa à morte da cidade. A racionalidade recusa a cidade como momento, ignora a pequena escala, e só a admite como instrumento, "a cidade, ou o que resta dela, é construída ou remanejada como se fosse uma soma ou combinatória de elementos" (LEFEBVRE, 2001, p. 82). Os modernistas rejeitaram as cidades e seu espaço, focando nas construções individuais e desprezando o papel do espaço urbano como local de encontro.

A ênfase, esclarecem Rogers e Gumuchdjian (2001), está na separação ao invés de basear-se na comunidade e nas relações sociais, e as atividades são organizadas objetivando maximizar o lucro para os comerciantes e empresários. Gehl (2013, p. 4) ironiza ao afirmar que "se alguém pedisse a uma equipe de planejamento para reduzir drasticamente a vida entre edifícios, eles não encontrariam um método mais efetivo do que a utilização dos princípios modernistas de planejamento".

Esclarece Gehl (2013) que, até 1960, as cidades eram projetadas e desenvolvidas com base em séculos de experiência e em consonância com seus habitantes, no entanto as teorias e ideologias modernistas substituíram esse modo de planejamento e sua tradição como base para o desenvolvimento. No entanto, o modernismo, assinala o autor, compreendeu a cidade 
como máquina, com suas partes separadas por função e onde a escala de planejamento segue a ordem edifícios, espaço e só por último, pessoas.

A vida urbana, assim como o espaço urbano, já não era mais prioridade no processo de planejamento moderno. O rumo dos acontecimentos não só reduziu as oportunidades para as pessoas e para o pedestrianismo - com o planejamento voltado para os automóveis - como também sitiou as funções culturais e sociais do espaço da cidade (GEHL, 2013).

\section{O DESENVOLVIMENTO LOCAL E A DIMENSÃO HUMANA}

Como já mencionado acima por Lefebvre (2001), a cidade - como reflexo da sociedade e de suas ações sobre um território - se modifica sempre quando a sociedade em seu conjunto se modifica, e não só os processos globais modelam o espaço urbano, como principalmente os modos de produção e de desenvolvimento adotados por essa sociedade. Castells (2016) corrobora com esse argumento, pontuando que esses modos de desenvolvimento e produção modelam todo o comportamento social, até mesmo a comunicação simbólica de uma sociedade, já que as relações de produção difundem-se por todo conjunto de relações e estruturas sociais, modificando-os.

O crescimento econômico, caracterizado por conotações quantitativas, não é por si só sinônimo de desenvolvimento, que "implica também, e essencialmente, dimensões concernentes tanto à qualidade do processo de evolução econômico-social quanto à amplitude participativo-beneficiária de toda a população por ele abrangida" (ÁVILA et al, 2001, p. 23). A teoria capitalista vigente prega que o desenvolvimento social é consequência direta do crescimento econômico, mas, quando se analisa historicamente os países, especialmente os subdesenvolvidos, é possível ver que tal teoria não se comprova, pelo contrário, em vários países o aumento da riqueza econômica, ao invés de impulsionar a qualidade de vida, tem a agravado, especialmente na questão da segregação social e distribuição desigual de renda.

Segundo Claxton (1994), a imposição do conceito de desenvolvimento predominantemente econômico, produziu rupturas das tradições e dos sistemas socioculturais e socioeconômicos. Já alertava Capra (1982) que a visão mecanicista e o crescimento econômico indefinido, mais cedo ou mais tarde, iriam interferir no equilíbrio natural e causar danos graves à sociedade e ao mundo, necessitando de uma transformação radical e de uma abordagem sistêmica. A concepção sistêmica, de acordo com o autor, compreende o mundo em termos de relações e de integração, sendo fundamental para entender e enfrentar os desafios da nova realidade, do atual mundo em rede.

Por conseguinte é preciso reconhecer que as teorias sociais e econômicas, que dirigem e sustentam o processo de desenvolvimento, estão não apenas incompletas, mas também inadequadas. Destaca Lefebvre (2001, p. 124) a necessidade de orientar o crescimento na direção do desenvolvimento, na direção da sociedade urbana, com as necessidades humanas em foco, sendo "essencial não mais visar o crescimento econômico pelo crescimento, ideologia 'economista' que acoberta intenções estratégicas: o superlucro e a superexploração capitalistas, o domínio do econômico [...] em proveito do Estado. Os conceitos de equilíbrio econômico, de crescimento harmonioso [...] devem se subordinar aos conceitos virtualmente mais poderosos de desenvolvimento".

Dessa forma, as frentes social e econômica do desenvolvimento devem estar aliadas, "a social, potencializando as pessoas para se tornarem sujeitos e agentes inclusive da econômica, e 
a econômica, ensejando sustentação material e apoio instrumental ao alavancamento da social no curso da cadeia processual", a fim de garantir a qualidade do desenvolvimento em todas as dimensões da vida humana (ÁVILA et al, 2001, p. 24). Logo, o ser humano, como protagonista de seu futuro, deve ser o alvo central do desenvolvimento.

O desenvolvimento local, na concepção de Ávila (2000), é o processo de "desabrochamento" do potencial interno de uma determinada comunidade, suas habilidades e capacidades, em que dá autonomia para essa comunidade gerenciar seu potencial a fim de buscar soluções para os eventuais problemas do seu cotidiano, em que é a própria comunidade que assume e põe em prática seus saberes e capacidades para gestão de suas condições e qualidade de vida, e as participações de quaisquer agentes externos servem como o meio impulsor do progresso. No entanto o desenvolvimento local deve conciliar promoção externa com iniciativas internas, já que a ação isolada de grupos locais não consegue ter impacto real se não for fortalecido pela ação de planejamentos e políticas externas, sendo necessário esse planejamento externo a fim de criar maior autonomia local (MAX-NEEF, 1991).

Em vista disso, a participação ativa da comunidade é primordial no processo de desenvolvimento local. Ao invés de serem objetos de desenvolvimento, as pessoas necessitam ser protagonistas do processo, no qual o Estado deve assumir o papel de encorajar processos sinérgicos em nível local. O desenvolvimento local compreende-se, então, em contraposição à hegemonia do econômico, em que o ser humano prevalece, sempre, em relação ao econômico, implicando um modelo mais coerente, a fim de satisfazer as necessidades humanas de modo igualitário, garantir a qualidade de vida e o bem-estar social (MARQUES, 2013).

O local corresponde à escala de vida, pois é no sistema territorial local que ocorre o desenvolvimento da vida em todas as suas dimensões. Analisa Carlos (1996, p. 20) que "a produção espacial realiza-se no plano do cotidiano e aparece nas formas de apropriação, utilização e ocupação de um determinado lugar", sendo, então, base de reprodução da vida, produto das relações humanas entre si e com o espaço, formando uma rede de significados tecidos pela história e cultura. O sistema territorial local é compreendido como produto e produção, já ao ser produzido por uma sociedade, também passa a produzi-la, com efeito de circularidade retroativa, em um processo dinâmico e constante.

O desenvolvimento a partir da realidade local é voltado para realizar as necessidades humanas. Portanto a dimensão humana do desenvolvimento se foca na:

[...] satisfação das necessidades humanas fundamentais, geração do crescimento do nível de autossuficiência e na construção de articulações orgânicas das pessoas com a natureza e tecnologia, dos processos globais com atividade local, do pessoal com o social, do planejamento com autonomia e da sociedade civil com o Estado. (MAX-NEEF, 1991, p..8).

O melhor método de desenvolvimento é o que irá causar a maior melhoria na qualidade de vida de um grupo social, o que depende das possibilidades de satisfazer adequadamente as necessidades humanas fundamentais. A base do desenvolvimento na escala humana é a criação das condições na qual as pessoas são protagonistas de seu futuro.

Para Max-Neef (1991, p. 8), alcançar a transformação "de uma pessoa-objeto para uma pessoa-sujeito no processo de desenvolvimento é, entre outras coisas, um problema de escala. Não há possibilidade para a participação ativa das pessoas em sistemas gigantescos organizados hierarquicamente e onde as decisões se dão de cima para baixo". Somente quando um processo desenvolvimento é voltado para potencializar os sujeitos locais e colocá-los no papel de sujeitos 
ativos, é que ele será verdadeiramente exitoso, pois, dessa forma, será voltado às pessoas, à dimensão humana do local.

\section{A HUMANIZAÇÃO DO ESPAÇO URBANO: CIDADES PARA PESSOAS}

Os novos desafios globais salientam a importância da preocupação focada na dimensão humana. Pela primeira vez, após a virada do milênio, a maior parte da população global é urbana e não rural, fazendo com que as cidades - tanto as existentes como as novas - tenham que adaptar seu espaço e fazer mudanças cruciais em seu planejamento e suas prioridades no espaço urbano. Gehl (2013, p. 6) afirma que se deve destacar "como objetivo-chave para o futuro, um maior foco sobre as necessidades das pessoas". A dimensão humana nas cidades é fundamental para um novo modo de planejamento.

O desenvolvimento da sociedade, de tecnologia construtiva e economia, resultou em áreas urbanas e edifícios de escala sem precedentes, introduzindo grandes distâncias, prédios altos e arquitetura rápida. Enquanto as cidades do passado foram construídas pelo acréscimo de edificações ao longo dos espaços públicos, resultando em cidades com escala adaptada aos sentidos e potencial do ser humano, as áreas urbanas hoje são, muitas vezes, agrupamentos de edifícios isolados e aleatórios, entre estacionamentos e grandes vias (GEHL, 2013). Ao longo da história, o espaço urbano funcionava como ponto de encontro e fórum social, até o triunfo dos ideais modernistas de planejamento urbano aliados com a invasão dos automóveis. No entanto a humanização das cidades implica o fortalecimento da função social do espaço urbano como local de encontro, contribuindo para os objetivos da sustentabilidade social e para uma sociedade democrática e aberta.

Contra os princípios modernistas de setorização da cidade, Jacobs (2011) defende a diversidade econômica e social- de usos, usuários e edificações- como um meio capaz de garantir a vitalidade urbana. As cidades possuem a necessidade de uma diversidade de usos mais complexa e densa, para propiciar uma sustentação mútua e constante, tanto econômica quanto social. Seus componentes podem se diferir muito, mas devem ser complementares. "É tolice planejar a aparência de uma cidade sem saber que tipo de ordem inata e funcional ela possui", a ideia fundamental do urbanismo desse modo é procurar entender a ordem social e econômica sob a aparência das cidades, procurando adquirir e aplicar todo conhecimento sobre as cidades que seja útil e verdadeiro (JACOBS, 2011).

Não é possível saber qual solução propor a um espaço se não se sabe como este funciona, como as relações se estabelecem, de que maneira é usado, do que ele mais necessita. Deve-se ater a esse tipo de conhecimento, e não em suposições de como a cidade deveria ser e parecer. Para isso, é necessário estudar a vida pública no espaço urbano, analisando a situação real da área, seus problemas, suas particularidades e potencialidades, procurando evidenciar as diferentes maneiras que o local pode ser modificado para atender a escala humana.

Ao tentar entender o desempenho de uma cidade, "as boas informações vêm da observação do que ocorre no plano palpável e concreto, e não no plano metafísico" (JACOBS, 2011). Desse modo, a escala de vida é vista como expressão da relação que a comunidade estabelece entre si e com o ambiente vivido, sendo peça essencial para um bom estudo de planejamento urbano, pois auxilia na compreensão da forma que o local é utilizado e como as relações sociais se manifestam nesse espaço.

INTERAÇÕES, Campo Grande, MS, v. 19, n. 4, p. 739-755, out./dez. 2018 
Observar a realidade do ambiente vivido, sua dinâmica e complexidade é essencial para compreender a natureza interconectada das diferentes dimensões do sistema urbano. Quando um espaço urbano passa por alterações, a comunidade que vive no local é afetada com estas, sejam positivas ou negativas, podendo alterar sua cultura, identidade e suas relações. Por conseguinte uma mudança no território modifica também o modo como população se identifica com ele; portanto as transformações urbanas devem ser condizentes com os desejos e necessidades da comunidade local, em um processo no qual os sujeitos irão dar valor ao local transformado, moldando-o ao seu uso e, ao mesmo tempo, irão ser moldados por esse local.

Logo, a humanização do espaço urbano é uma questão de escala. O urbanismo envolve trabalhar com níveis de escala diferentes, como a grande escala (tratamento holístico da cidade, bairros, funções, instalações de tráfego), a escala média (organização dos edifícios, disposições, espaço público) e a escala pequena (paisagem humana, escala da rua, ao nível dos olhos). Trabalhar com a escala menor é "chave para alcançar melhores condições para a dimensão humana", que deve estar integrada no planejamento e desenvolvimento de uma cidade, no entanto, para isso, é necessária uma mudança significante nos métodos habituais de pensamento e trabalho (GEHL, 2013, p. 195).

Um bom planejamento urbano, ainda que utilizando a escala menor como ponto de partida, exige trabalho que combine as três escalas de maneira holística. Esse ideal contrasta com a prática de planejamento urbano modernista, que prioriza os edifícios ao invés de priorizar o todo e o espaço urbano. As cidades na escala humana implicam priorizar primeiro as pessoas, depois o espaço e por último os edifícios.

O ponto de partida ao projetar cidades para pessoas, logo, é a mobilidade e os sentidos humanos. A escala humana demanda ambientes, mobiliário e elementos urbanos voltados para a utilização com conforto pelas pessoas, como também o modo com que as pessoas percebem o ambiente urbano. Supõe trabalhar com pedestres, criando bons espaços para eles ao levar em consideração as possibilidades e limitações do corpo humano, e "independentemente de ideologias de planejamento ou condições econômicas, a gestão cuidadosa da dimensão humana em todos os tipos de cidades e áreas urbanas deve ser um requisito universal" (GEHL, 2013, p. 118).

Quando se tem como prioridade a dimensão humana e o encontro entre as pessoas, é essencial estimular a vida nas cidades como processo e atração principal. A vida urbana, segundo Jacobs (2011, p. 75), "só surge quando existem as oportunidades concretas, tangíveis, de que necessita [...] se elas não existirem, os contatos públicos nas ruas também não existirão". O espaço urbano deve oferecer oportunidades, convites e ser acessível para pessoas de diferentes grupos sociais e econômicos. Convite para Gehl (2013) é a palavra-chave quando se trata sobre espaço urbano, e a qualidade urbana na pequena escala é essencial.

Uma política urbana integrada, que contemple a vida na cidade, a segurança, sustentabilidade e saúde é crucial para melhorar a qualidade de vida urbana por meio de um planejamento urbano holístico, garantindo que todos os habitantes de uma cidade se sintam convidados a usufruir dos espaços urbanos. Esses aspectos são chave para a humanização do espaço urbano, podendo ser reforçados, principalmente, com o aumento da preocupação com o pedestre e com a vida na cidade em geral.

Esclarece Gehl (2013, p. 7) que "existem conexões diretas entre as melhorias para as pessoas no espaço da cidade e as visões para obter cidades vivas, seguras, sustentáveis e saudáveis". 
Quando se melhoram as condições para os pedestres, é reforçada a vida da cidade, pois o convite não é apenas para caminhar, mas sim participar de uma vida urbana versátil e variada. A preocupação com a dimensão humana no planejamento urbano reflete a exigência pela melhoria da qualidade de vida urbana.

O resgate do espaço urbano e de sua função social, atualmente, está surgindo com mais força através do placemaking, processo no qual o desenvolvimento local encontra a humanização das cidades, unindo suas fundamentações teóricas e exercendo-as na prática. O placemaking (criação de lugares) pode ser descrito como "um processo que transforma qualquer espaço público em um lugar que responde às necessidades e desejos da comunidade, convidando as pessoas a viver a cidade, conectar-se, e ser mais saudáveis e felizes" (HEEMANN, 2015, p. 278).

Assim como no desenvolvimento local, o placemaking exige o engajamento das pessoas no processo de construção e apropriação de um espaço, pensando no público ao invés dos interesses privados, construindo para todos e por todos, e não pelos poderes políticos ou corporativos. Fundamenta-se no empoderamento de diferentes atores de uma comunidade e do envolvimento de atores locais a fim de garantir que os espaços expressem uma identidade coletiva, resultando em cidades genuínas que reforçam o patrimônio cultural e os valores sociais locais (PÉREZ, 2015).

Quando o placemaking e seus princípios estão incorporados no processo de planejamento, ao invés de ser tratado como recurso auxiliar, seu resultado sempre será uma cidade na escala humana, uma vez que o poder de mudança está nas mãos daqueles que vivem e usufruem do local, tornando as transformações do espaço bem-vindas e contextuais, e não impostas. O planejamento urbano definido em função dos habitantes de uma cidade, com seu tecido urbano, com a vida e interação de usos, opõe-se às concepções do planejamento ortodoxo, do qual Jacobs (2011, p. 144) afirma que "a diferença está em lidar com organismos vivos e complexos, capazes de definir seu próprio destino, e lidar com uma comunidade fixa e inerte, meramente capaz apenas de proteger (se tanto) o que Ihe foi outorgado".

Compreender a vida no espaço urbano pressupõe compreender os princípios que fundamentam os comportamentos nas cidades; dessa forma, ressalta Gehl (2013) que a vida na cidade e consideração pelas pessoas no espaço urbano devem ter um papel-chave no planejamento urbano, sendo um requisito universal para os processos de planejamento e para atender aos desafios do século XXI. Jacobs (2011, p. 263) destaca que as cidades são locais dinâmicos, que proporcionam solo fértil para os planos de seus habitantes, possuindo "capacidade de oferecer algo a todos, mas só porque e quando são criadas por todos". As cidades precisam ser a interação entre forma e vida e um modelo de desenvolvimento urbano só é eficiente se contempla essa condição.

\section{DIREITO À CIDADE E CIDADES PARA TODOS COMO CENTRO DAS POLÍTICAS PÚBLICAS}

A Organização das Nações Unidas (ONU, 2016, p. 6) define o direito à cidade como "o direito de todos os habitantes presentes e futuros, de ocupar, usar e produzir cidades justas, inclusivas e sustentáveis, definidas como um bem comum essencial à qualidade de vida. $\mathrm{O}$ direito à cidade também implica responsabilidades sobre os governos e às pessoas de reivindicarem, defenderem e promoverem esse direito". Dessa maneira, ele deve estar no centro 
do planejamento e das políticas urbanas, sendo considerado como um novo paradigma para o desenvolvimento urbano, buscando lidar com os principais desafios relacionados às cidades e assentamentos humanos.

Não há um modelo único a ser implantado e promovido para todas as áreas urbanas, mas sim princípios à vida urbana para promoção de cidades centradas nas pessoas. Como cada local possui diferentes contextos sociais, históricos e culturais, as soluções finais adotadas por uma comunidade dificilmente será exatamente a mesma que de outras áreas urbanas.

A Nova Agenda Urbana, documento criado na terceira Conferência das Nações Unidas sobre Moradia e Desenvolvimento Urbano Sustentável (Habitat III) em 2016, é vista como uma extensão da Agenda 2030 para o desenvolvimento sustentável e com os Objetivos de Desenvolvimento Sustentável (particularmente o ODS 11 de criar cidades inclusivas, seguras, resilientes e sustentáveis), sendo criada para orientar a urbanização sustentável pelos próximos 20 anos.

O direito à cidade é utilizado com estrutura central da Nova Agenda Urbana e dos documentos de políticas da Habitat III, a fim de fornecer base para repensar a urbanização, tendo como perspectiva o cumprimento eficaz dos direitos humanos na sua aplicação às cidades ao adotar uma mudança no modelo urbano predominante. Procura estabelecer diretrizes para repensar a maneira com que as cidades e os assentamentos humanos são planejados, financiados, desenvolvidos, governados e gerenciados, incentivando todos os níveis de governo e da sociedade a fazerem parte dos compromissos pelo desenvolvimento urbano, objetivando minimizar injustiças socioespaciais, promover crescimento econômico sustentável e inclusivo, aumentar a equidade, a inclusão, participação política e gerar uma vida digna para seus habitantes (ONU, 2017).

O direito à cidade possui três pilares, nos documentos das Nações Unidas, desenvolvidos com recomendações concretas para superar os problemas urbanos, em que ações-chave são especificadas para atingir seus objetivos.

1. Distribuição espacialmente justa de recursos: terra para habitação e meios de vida, e a de-comoditização do espaço urbano; bens públicos urbanos, espaço público, e biodiversidade; acesso a serviços básicos e infraestrutura, e controle de poluição; assentamentos de habitação informais e não planejados; resiliência; mudança do clima, gestão de riscos e desastres;

2. Ação política: governança inclusiva; planejamento urbano inclusivo; cidadania; fomento à participação, transparência e democratização;

3. Diversidade cultural, econômica e social: reconhecimento dos atores sociais; abrangência de identidade, prática cultural, diversidade, e patrimônio; cidades mais seguras; meios de vida, bem-estar; risco de pobreza e vulnerabilidades empregatícias; economia inclusiva e economia solidária.

Cada pilar abrange diferentes pontos, compreendendo cinco áreas transversais: estratégias espaciais urbanas, governança, economia, aspectos sociais, e aspectos ambientais. Estas têm como base os direitos humanos- engloba todos os direitos civis, políticos, econômicos, sociais, culturais e ambientais- considerando as cidades como bens comuns e como lugares que se empenham em garantir uma vida digna e plena para seus habitantes.

Dessa maneira, busca assegurar que todos tenham acesso aos recursos urbanos, serviços, bens e oportunidades de vida nas cidades, garantir a participação efetiva dos cidadãos nas polí- 
ticas locais, assegurando a distribuição justa dos recursos pelo Poder Público e reconhecendo a diversidade sociocultural como fonte de melhoria social. Também clama pelo papel reforçado de todos os habitantes do espaço urbano, e de uma aliança estratégica dos atores-chave urbanos, perpassando as escalas territoriais, sociais e econômicas e se realizando nos diferentes níveis local, nacional e global (ONU, 2016).

A mudança nas políticas públicas e a maneira como as cidades são gerenciadas e planejadas são pontos críticos para o espaço urbano. Rogers e Gumuchdjian (2001, p. 16) destacam que "as cidades só podem refletir os valores, compromissos e resoluções da sociedade que abrigam. Portanto o sucesso de uma cidade depende de seus habitantes e do poder público, da prioridade que ambos dão à criação e manutenção de um ambiente urbano e humano".

O planejamento e o desenho das cidades devem se aliar às políticas públicas para empoderar os cidadãos e possibilitar que diferentes grupos sociais superem as desigualdades e vulnerabilidades, a fim de tornar todos os habitantes em agentes ativos para construir e se beneficiar das cidades. Entretanto isso não acontece com políticas verticalizadas, impostas pelo Poder Público, que não leva em consideração as relações horizontais e as características particulares da comunidade local.

A cidade para todos implica o reconhecimento dos múltiplos atores de um espaço urbano, buscando alcançar o mesmo poder de fala e influência na construção da cidade para todos. O desafio se encontra na criação da participação efetiva desses atores, em todos os processos de construção, transformação e governança das cidades, por meio dos princípios do direito à cidade, com a dimensão humana como ponto de partida universal em quaisquer processos e modelos de desenvolvimento e planejamento.

\section{CONSIDERAÇÕES FINAIS}

A dimensão humana é uma questão primordial no mundo todo, independente do nível de desenvolvimento econômico dos países. Mais da metade da população mundial vive em áreas urbanas, que estão crescendo em um ritmo acelerado, tornando a questão da qualidade do espaço urbano indispensável. O rápido crescimento da população urbana sobrecarregou os serviços públicos, sistemas de tráfego e os espaços públicos, reduzindo drasticamente a mobilidade e as oportunidades de autoexpressão, em que o crescimento econômico acompanha a redução da qualidade de vida urbana, especialmente para os grupos sociais mais pobres.

Os modelos de urbanização que privilegiam o crescimento econômico sobre o desenvolvimento e o bem-estar humano lesam os cidadãos e o direito à cidade, pois não evitam as consequências negativas do crescimento e não priorizam a dignidade humana, a inclusão, a qualidade de vida e o bem-estar, e a solidariedade. Diante destes desafios - de mobilidade, saúde, emprego, moradia, segurança, educação e serviços - há um consenso da necessidade de enfrentá-los com um novo paradigma e modelo de desenvolvimento holístico, para guiar politicas públicas e ações governamentais, focando na construção de cidades para todos, sendo vital garantir que a dimensão humana do planejamento urbano seja integrada minuciosamente no desenvolvimento urbano.

O planejamento urbano deve ter como ponto de partida o ser humano, trabalhando, dessa forma, com a escala de vida, com o local, na abordagem "de baixo para cima". O processo que implica essa abordagem é o próprio desenvolvimento local. Ao levar em consideração as caracte- 
rísticas do local e de sua população, potencializando-os e visando à satisfação das necessidades humanas, o desenvolvimento local é o processo que melhor garante a qualidade de vida dos sujeitos, pois representa seus interesses, fortalece a identidade local e estimula a diversidade e a multiplicidade de matrizes culturais presentes na sociedade, sobrepondo-se às dimensões estritamente econômicas.

Levar em consideração as necessidades das pessoas que utilizam o espaço urbano e considerar a escala do cotidiano, criando ambientes que atendam à dimensão humana, é ponto fundamental para garantir melhoria na qualidade de vida urbana. As cidades na dimensão humana, defendida por Gehl e Jacobs, e o desenvolvimento local e a escala humana, propostos, principalmente, por Max-Neef e Ávila, possuem a mesma essência, os mesmos valores e o mesmo objetivo: Tornar as pessoas ponto de partida de qualquer processo de desenvolvimento, e o Direito à Cidade é a base fundamental para alcançar esse objetivo.

Desse modo, ainda que com diferentes nomenclaturas, é possível correlacionar os conceitos e princípios de desenvolvimento local, direito à cidade, cidades para pessoas e placemaking, como processos que implicam a humanização do espaço urbano por meio do protagonismo e participação ativa das comunidades, a fim da apropriação efetiva do espaço urbano, do cumprimento dos direitos humanos e da priorização das pessoas que vivem no local, acima de qualquer outro ponto.

A humanização do espaço urbano requer o foco nas práticas cotidianas e na compreensão da vida urbana para que as pessoas se tornem o centro do planejamento das políticas públicas. É absolutamente necessário desenvolver novas maneiras de conceber e praticar as políticas públicas para que elas possam representar as necessidades e interesses das pessoas e para evitar a exclusão, seja no âmbito politico, social ou cultural. Nesse contexto, o poder público tem função crucial na promoção, garantia e proteção dos direitos humanos no espaço urbano. É este um desafio tanto para o Estado como para a sociedade civil, já que o direito à cidade também é uma responsabilidade sobre os governos, e às pessoas de reivindicarem, promoverem e defenderem tal direito.

Diante do que foi discutido no presente artigo, o processo de desenvolvimento local deve ser visto como uma forma de garantir o direito à cidade, a fim de emancipar uma sociedade e garantir sua inclusão no planejamento e processo de produção do espaço urbano, ao estimular a organização e participação social aliadas à ação colaborativa do poder público, sempre visando à realização das necessidades humanas e melhoria da qualidade de vida no ambiente urbano.

\section{REFERÊNCIAS}

ÁVILA, Vicente Fidelis de et al. Formação educacional em desenvolvimento local: relato de estudo em grupo e análise de conceitos. 2. ed. Campo Grande, MS: UCDB, 2001.

ÁVILA, Vicente Fidelis de. Pressupostos para formação educacional em desenvolvimento local. Interações, Campo Grande, MS, v. 1, n. 1, p. 63-76, set. 2000.

CAPRA, Fritjof. O ponto de mutação. São Paulo: Cultrix, 1982.

CARLOS, Ana Fani Alessandri. O lugar no/do mundo. São Paulo: Hucitec, 1996.

CASTELLS, Manuel. A sociedade em rede. São Paulo: Paz e Terra, 2016.

CHOAY, Françoise. O urbanismo. 17. ed. São Paulo: Perspectiva, 2003.

CLAXTON, Mervyn. Culture and development: a study. Paris: UNESCO, 1994. 
GEHL, Jan. Cidades para pessoas. 2. ed. São Paulo: Perspectiva, 2013.

HALL, Peter. Cidades do amanhã: uma história intelectual do planejamento e do projeto urbanos no século XX. 4. ed. São Paulo: Perspectiva, 2016.

HARVEY, David. Cidades rebeldes: do direito à cidade à revolução urbana. São Paulo: Martins Fontes, 2014. HEEMANN, Jeniffer. A ciência da diversão em São Paulo. In: KARSSENBERGER, H. et al. (Ed.). A cidade ao nivel dos olhos: lições para os plinths. Traduzido por Paulo Horn Regal e Renee Nycolaas. Porto Alegre: EDIPUCRS, 2015. p. 278-81.

HOWARD, Ebenezer. Garden cities of to-morrow. Londres: Swan Sonnenschein \& co. 1902.

JACOBS, Jane. Morte e vida das grandes cidades. 3. ed. São Paulo: Martins Fontes, 2011.

LE CORBUSIER. Por uma arquitetura. 6. ed. São Paulo: Perspectiva, 2002.

Planejamento urbano. 3. ed. São Paulo: Perspectiva, 2000.

LEFEBVRE, Henri. O direito à cidade. São Paulo: Centauro, 2001.

MARQUES, Heitor Romero. Desarrollo local en la escala humana: una exigencia del siglo XXI. Campo Grande, MS: Gráfica Mundial, 2013.

MAX-NEEF, Manfred. Human scale development: conceptions, applications and further development. Contributions from Antonio Elizalde, Martin Hopenhayn. New York: Apex Press, 1991.

ORGANIZAÇÃO DAS NAÇÕES UNIDAS (ONU). Resolution adopted by the General Assembly on 23 December 2016. New Urban Agenda, 25 janeiro 2017.

Documento de Políticas a Habitat III. Direito à cidade e cidades para todos. 29 fev. 2016. Disponível em: <http://habitat3.org/wp-content/uploads/Policy-Paper-1-Portugue\%CC\%82s.pdf>. Acesso em: maio 2018.

PARK, Robert E. The city: suggestions for investigation of human behavior in the urban environment. Chicago: University of Chicago Press, 1925.

PÉREZ, Francisco Pailliè. Imaginar que um espaço pode ser diferente. In: Karssenberger, H. et al. (Ed.). A cidade ao nível dos olhos: lições para os plinths. Traduzido por Paulo Horn Regal e Renee Nycolaas. Porto Alegre: EDIPUCRS, 2015. p. 282-5.

ROGERS, Richard; GUMUCHDJIAN, Philip. Cidades para um pequeno planeta. Barcelona, Espanha: Editorial Gustavo Gili, 2001

\section{Sobre os autores:}

Lina Yule Queiroz de Oliveira: Mestranda do Programa de Pós-Graduação em Desenvolvimento Local - Universidade Católica Dom Bosco (UCDB). E-mail: lina_afowl@hotmail.com

Pedro Pereira Borges: Doutor e Mestre em Ciências Sociais pela Pontifícia Universidade Católica de São Paulo (PUC-SP). Licenciado em Filosofia e Pedagogia pela Universidade Católica Dom Bosco (UCDB), de Campo Grande, MS. Bacharel em Teologia pelo Instituto Santo Tomás de Aquino, de Belo Horizonte, MG, e pela Università Ponteficia Salesiana di Roma (UPS). Docente do Programa de Pós-Graduação em Desenvolvimento Local - Universidade Católica Dom Bosco (UCDB). E-mail: pobojari@ucdb.br 
